\title{
A voice from the streets about Spice
}

lan Millar draws on personal experience of living on the streets and living and working in hostels and day care centres. He volunteers with Pathway (www.pathway.org.uk), as part of its Expert by Experience programme, advising medical and political bodies on the healthcare of homeless people

In over 30 years of recreational drug use, I have never been as worried about any drug as I have about "Spice." Spice is a generic name for a range of synthetic recreational drugs, also known as "legal highs," that are spreading quickly on the streets.

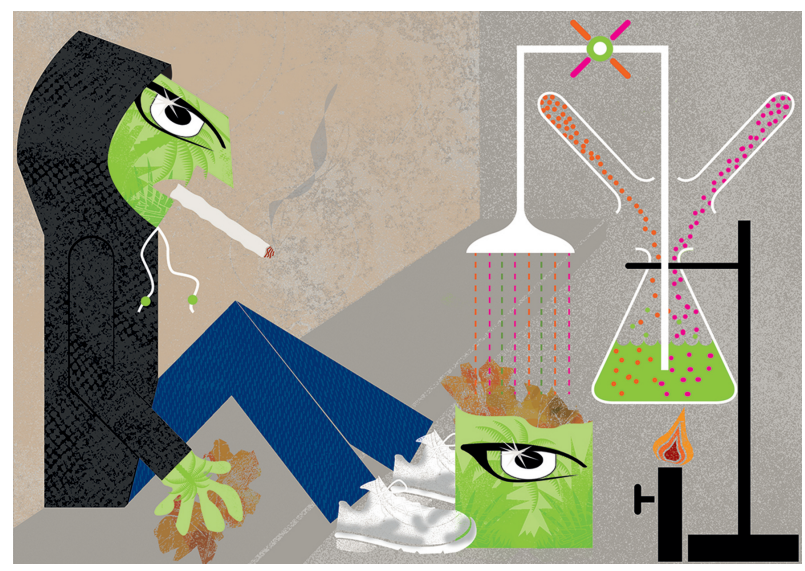

[Image: Rose Lloyd]

Last March I visited a hostel with 70 residents, four of whom were regular users of Spice. This year I stayed in a hostel with 30 residents, and more than half were daily users.

Spice is sold in bags of combustible vegetable matter, which has been sprayed with a variety of chemicals, each producing slightly different versions of the same type of buzz. Because of the way Spice is mass produced, there can be huge inconsistencies in its strength from batch to batch.

Spice is usually mixed with tobacco and smoked as a joint, but more experienced users smoke it neat in pipes. This produces a much more dramatic effect—similar to LSD or magic mushrooms - although Spice seems to be many times more powerful.

I have noticed that Spice triggers a heightened awareness of the senses, particularly hearing, as users quite often find noises amusing. One guy I looked after found the acoustics of the toilet bowl hilarious between bouts of projectile vomiting.

Depending on the mood that people are in when they take Spice, their imaginations run wild in any direction. A common trip I've seen is for users to believe they are communicating with aliens. It can be unsafe to try to restrain or inhibit them because in their mind you could be an alien invader; they may act in a panicked and violent manner, even attacking and biting those who are trying to treat them.

In my experience, users are prone to blackouts, which seem almost a brain reboot in response to sensory overload. If standing, users will start to go floppy and bend at the knees. They often collapse, opening up the possibility of serious physical harm.

Luckily, the effects do not last long, so users should be spoken to calmly and reassuringly; you should try to get them to sit or lie somewhere safe, and wait for about 15 minutes. By then they should be more coherent.

If you are not sure if someone has used Spice, smell his or her breath. A user's breath has an unpleasant acrid burnt smell, which is very pungent. You may also notice a change in the user's voice, with a slightly higher pitch-like when helium has been inhaled, but not as squeaky.

I've met a few people who have had no ill effects when withdrawing from prolonged use of Spice, but most people tell me they have classic withdrawal symptoms such as cramping, sweating, and twitching. I think the biggest worry is the psychological effect, as many people have told me that the use of Spice leads to very low moods, with thoughts of self harm or suicide.

We have absolutely no idea of the short term effects of using Spice, let alone the long term effects on the brain.

Every packet carries a warning that says it all: NOT FOR HUMAN CONSUMPTION.

I have never been as worried about any drug as I have about Spice

For series information: Rosamund Snow, patient editor, rsnow@bmj.com

Competing interests: I have read and understood BMJ policy on declaration of interests and declare the following: none.

Published by the BMJ Publishing Group Limited. For permission to use (where not already granted under a licence) please go to http://group.bmj.com/group/rights-licensing/ permissions 


\section{What you need to know}

- The range of drugs known as Spice is a growing problem on the streets and may already be affecting some of your patients

- If you suspect a patient is using Spice, look for clues such as a strong burnt smell on his or her breath

- Don't get in the way of people who are using this drug; talk calmly and try to get them to sit or lie down for 15 minutes until the initial high subsides

- Very little information is available on where Spice is affecting healthcare services and staff. If you are aware of this as a problem in your area, contact spiceaware@gmail.com to help map the spread of the drug

\section{Further resources}

Novel Psychoactive Treatment UK Network. Guidance on the clinical management of acute and chronic harms of club drugs and novel psychoactive substances (http://neptune-clinical-guidance.co.uk/wp-content/uploads/2015/03/NEPTUNE-Guidance-March-2015.pdf) 